\title{
A high calcium diet containing nonfat dry milk reduces weight gain and associated adipose tissue inflammation in diet-induced obese mice when compared to high calcium alone
}

\author{
Anthony P Thomas ${ }^{1 \dagger}$, Tamara N Dunn ${ }^{1 \dagger}$, Josephine B Drayton ${ }^{2}$, Pieter J Oort ${ }^{3}$ and Sean H Adams $s^{1,3^{*}}$
}

\begin{abstract}
Background: High dietary calcium (Ca) is reported to have anti-obesity and anti-inflammatory properties. Evidence for these properties of dietary $\mathrm{Ca}$ in animal models of polygenic obesity have been confounded by the inclusion of dairy food components in experimental diets; thus, effect of Ca per se could not be deciphered. Furthermore, potential anti-inflammatory actions of $\mathrm{Ca}$ in vivo could not be dissociated from reduced adiposity.

Methods: We characterized adiposity along with metabolic and inflammatory phenotypes in diet-induced obese (DIO) mice fed 1 of 3 high fat diets (45\% energy) for 12 wk: control $(n=29)$, high-Ca $(n=30)$, or high-Ca + nonfat dry milk (NFDM) $(n=30)$.

Results: Mice fed high-Ca + NFDM had reduced body weight and adiposity compared to high-Ca mice $(P<$ 0.001). Surprisingly, the high-Ca mice had increased adiposity compared to lower-Ca controls $(P<0.001)$.

Hyperphagia and increased feed efficiency contributed to obesity development in high-Ca mice, in contrast to NFDM mice that displayed significantly reduced weight gain despite higher energy intake compared to controls ( $P$ < 0.001). mRNA markers of macrophages (e.g., CD68, CD11d) strongly correlated with body weight in all diet treatment groups, and most treatment differences in WAT inflammatory factor mRNA abundances were lost when controlling for body weight gain as a covariate.
\end{abstract}

Conclusions: The results indicate that high dietary Ca is not sufficient to dampen obesity-related phenotypes in DIO mice, and in fact exacerbates weight gain and hyperphagia. The data further suggest that putative anti-obesity properties of dairy emanate from food components beyond Ca.

Keywords: Calcitriol, calcium, dairy, obesity, inflammation

\section{Background}

Epidemiological or cross-sectional studies in human populations support an inverse relationship between dietary calcium $(\mathrm{Ca})$ and dairy food consumption with obesity. Several clinical weight loss intervention studies that included high-Ca or dairy foods indicated a positive effect on body fat loss $[1,2]$, but this has not been universally observed [3], suggesting that these effects are context-

\footnotetext{
* Correspondence: sean.h.adams@ars.usda.gov

+ Contributed equally

'Department of Nutrition, University of California, One Shields Avenue, Davis, CA, USA

Full list of author information is available at the end of the article
}

specific (e.g., dependent upon the specific population, dietary Ca status, type of dairy food, or provision of elemental $\mathrm{Ca}$ vs. $\mathrm{Ca}$ in a dairy matrix). In contrast, fat loss or reduced weight gain in response to high-Ca plus dairy protein in rodent obesity models has been consistently reported [4-7]. The mechanisms underlying the metabolic effects of $\mathrm{Ca}$ and dairy foods to reduce adiposity remain to be elucidated. Increased fecal fat loss due to the formation of indigestible Ca soaps in the gastrointestinal tract has been proposed as a possible mechanism by which high dietary Ca reduces adiposity [8]. Research from one group has provided evidence in vitro and in the aP2-agouti transgenic mouse model of diet-induced obesity for a potential
() Biomed Central 
role of the calcitrophic hormone 1,25-dihydroxyvitamin D (calcitriol) in promoting adipocyte lipogenesis and inhibiting lipolysis, thus encouraging adipocyte lipid accumulation [9-11]. According to this model, increasing dietary $\mathrm{Ca}$ would suppress circulating calcitriol, discouraging energy storage and white adipose tissue (WAT) expansion.

Dietary Ca may also impact inflammatory phenotypes associated with obesity. Chronic inflammation of WAT, especially in visceral depots, contributes to the pathogenesis of obesity-related insulin resistance [12-14], and WAT macrophages are a prominent source of pro-inflammatory cytokine production [15-18]. Calcitriol increased proinflammatory cytokine gene expression and secretion from cultured adipocytes and macrophages, and this response was dependent on intracellular $\mathrm{Ca}$-provoked reactive oxygen species (ROS) generation; co-culture of both cell types increased gene expression and protein secretion of pro-inflammatory cytokines, which was further enhanced by calcitriol [19]. In vivo evidence for anti-inflammatory properties of high dietary Ca was demonstrated in the aP2-agouti transgenic mouse obesity model in which increased dietary $\mathrm{Ca}$ was associated with reduced plasma calcitriol [20,21]. Despite a potential mechanism for direct anti-inflammatory properties of dietary Ca through suppression of circulating calcitriol, reduced inflammation could not be dissociated from lower body weight and adiposity in studies of the aP2-agouti transgenic mice. Furthermore, one cannot exclude a confounding effect of adipose agouti protein overexpression on these phenotypes, or possible effects of agouti expression in macrophages since the aP2 promoter can be activated in both macrophages and fat cells. Thus, further research is necessary to confirm potential anti-inflammatory properties of high dietary $\mathrm{Ca}$ and/or dairy in polygenic obesity models while controlling for body weight and adiposity changes typically observed in animals fed these diets.

Additional bioactive components of dairy foods (e.g. branched chain amino acids, peptide fragments with angiotensin converting enzyme (ACE)-inhibitory properties) might contribute to anti-obesity/anti-inflammatory outcomes, since high $\mathrm{Ca}$ in a dairy matrix yielded greater effects vs. elemental $\mathrm{Ca}$ alone in aP2-agouti mice [22]. Studies demonstrating an anti-obesity effect of increased dietary $\mathrm{Ca}$ in polygenic obesity models have been only in the context of nonfat dry milk (NFDM) or whey providing all dietary protein $[4,6,7]$. Thus, comparing high $\mathrm{Ca}$ diet in matrices containing differing protein and carbohydrate sources (dairy and non-dairy) is of interest to understand if non-Ca factors in dairy foods could play a role in regulation of metabolism and obesity-associated inflammation.

To address whether dietary Ca can impact obesity phenotypes and to understand if putative anti-inflammatory effects of high-Ca or dairy-based diets are yoked to body weight, we investigated the potential anti-obesity and antiinflammatory effects of high dietary $\mathrm{Ca}$ in a well-characterized polygenic mouse model of diet-induced obesity (DIO): male C57BL/6J mice display susceptibility to dietinduced obesity and glucose intolerance when fed a high fat diet [23] and we have previously described obesity with associated inflammation and impaired glucose homeostasis when feeding these mice a diet providing $45 \%$ energy as fat (with soy- and sucrose/cornstarch-based protein and carbohydrate sources, respectively) for up to $12 \mathrm{wk}$ [24]. We hypothesized that independent of differences in body weight gain, DIO mice fed high-Ca would have reduced body weight, decreased adiposity, and improved metabolic and inflammatory phenotypes compared to control mice fed a lower Ca diet. Our study design also enabled a comparison of metabolic and inflammatory outcomes in highCa DIO mice relative to animals fed high-Ca in a dairy matrix (NFDM as the sole protein source and containing primarily dairy-based carbohydrates).

\section{Materials and methods DIO Mice}

All mouse protocols were approved by the University of California at Davis Institutional Animal Care and Use Committee according to Animal Welfare Act guidelines. Four-wk-old male C57BL/6J mice were purchased from the Jackson Laboratory and individually housed under standard temperature $\left(20-22^{\circ} \mathrm{C}\right)$ and light/dark cycle (12 h:12 h) conditions in a pathogen-free facility. Individually-housed mice were fed Picolab ${ }^{\circledR}$ Mouse Diet 20 (Purina LabDiet $^{\circledR}$ ) providing $\sim 22, \sim 22$, and $\sim 56 \%$ energy as protein, fat, and carbohydrate, respectively, for a $1 \mathrm{wk}$ acclimation period. Weight matched mice were randomly assigned to purified experimental diets containing 45\% energy as fat (Table 1) for $12 \mathrm{wk}$. Treatment groups were: soy proteinbased control ( $0.5 \% \mathrm{Ca}, n=29$; Control), soy protein-based high-Ca $(1.5 \% \mathrm{Ca}, n=30$; high-Ca), or high-Ca in the context of nonfat dry milk protein and carbohydrates $(1.5 \%$ $\mathrm{Ca}, n=30$; high-Ca + NFDM). In the case of the NFDM diet, to ensure equal macronutrient energy contribution compared to the other diets while maintaining a dairy nutrient matrix, protein (casein and whey-derived lactalbumin) and carbohydrate (galactose + glucose, the components of lactose) were added. $\mathrm{Ca}$ phosphate $\left(\mathrm{CaPO}_{4}\right)$ was added to the soy-protein based diets to match that naturally-derived from NFDM (to control for type of dietary $\mathrm{Ca}$ ), with $\mathrm{Ca}$ carbonate providing all additional $\mathrm{Ca}$ to the experimental diets as typically used in rodent studies comparing different dietary $\mathrm{Ca}$. Cellulose content was adjusted accordingly to account for added $\mathrm{Ca}$ in the high-Ca diets to ensure matched macro and micronutrient content of diets, and amounts of fiber are all within the normal range used in purified mouse diets. The control diet and $12 \mathrm{wk}$ timeframe were previously shown to elicit obesity, 


\begin{tabular}{|c|c|c|c|}
\hline & \multicolumn{3}{|c|}{ Diet [product code] } \\
\hline & Control $(0.5 \% \mathrm{Ca})$ [TD.08511] & High-Ca (1.5\% Ca) [TD.09068] & High-Ca + NFDM [TD.09069] \\
\hline \multicolumn{4}{|l|}{ Ingredients (g/kg) } \\
\hline Isolated Soy Protein & 195 & 195 & 0 \\
\hline Milk Powder, skim & 0 & 0 & 400 \\
\hline Casein & 0 & 0 & 29.5 \\
\hline Lactalbumin & 0 & 0 & 7.5 \\
\hline DL-Methionine & 2.34 & 2.34 & 1.24 \\
\hline L-Cystine & 1 & 1 & 0.55 \\
\hline Sucrose & 190 & 190 & 0 \\
\hline Galactose & 0 & 0 & 18.5 \\
\hline Dextrose, monohydrate & 0 & 0 & 20.29 \\
\hline Corn Starch & 87.99 & 87.99 & 0 \\
\hline Maltodextrin & 200 & 200 & 200 \\
\hline Cellulose & 50 & 25.25 & 40 \\
\hline Lard & 205 & 205 & 205 \\
\hline Soybean Oil & 20 & 20 & 20 \\
\hline Mineral Mix w/o Ca \& P (98057) & 17 & 17 & 17 \\
\hline Calcium Phosphate, dibasic & 14.5 & 14.5 & 0 \\
\hline Calcium Carbonate & 1.1 & 26 & 24.5 \\
\hline Vitamin Mix, AIN-93-VX (94047) & 12.7 & 12.7 & 12.7 \\
\hline Choline Bitartrate & 3.2 & 3.2 & 3.2 \\
\hline TBHQ, antioxidant & 0.02 & 0.02 & 0.02 \\
\hline \multicolumn{4}{|l|}{ Macronutrients (\% by weight) } \\
\hline Protein & 17.3 & 17.3 & 17.2 \\
\hline Carbohydrate & 47.4 & 47.4 & 44.4 \\
\hline Fat & 23.4 & 23.4 & 22.8 \\
\hline \multicolumn{4}{|l|}{ Macronutrients (\% kcal) } \\
\hline Protein & 14.7 & 14.7 & 15.2 \\
\hline Carbohydrate & 40.4 & 40.4 & 39.3 \\
\hline Fat & 44.9 & 44.9 & 45.4 \\
\hline $\mathrm{KJ} / \mathrm{g}$ & 19.7 & 19.7 & 18.8 \\
\hline
\end{tabular}

*Diets formulated and produced by Harlan Teklad. NFDM, nonfat dry milk.

increased WAT inflammation, and insulin resistance in this model [24]. Mice were given free access to food and water with body weight and food intake (plus spillage) measurements made every $2-3 \mathrm{~d}$. Fecal collections over 48 $\mathrm{h}$ were made on a subset of randomly chosen mice $(n=$ $10 /$ group) at wk 10 . Feces were weighed and stored at $-80^{\circ}$ $\mathrm{C}$ until bomb calorimetry was performed by Covance Laboratories. Percent fecal energy loss was calculated from each animal's $48 \mathrm{~h}$ fecal energy loss and energy consumption. Glucose tolerance tests were administered on a subset of randomly chosen mice ( $n=15-16 /$ group) as described elsewhere [24]. At wk 12, mice were briefly food-deprived prior to tissue and blood collection as described in detail [24].

Total RNA Isolation and Gene Expression Analyses

Total RNA was isolated from whole retroperitoneal (RP) fat pads, cDNA was prepared, and 384-well quantitative
PCR utilizing gene-specific Taqman ${ }^{\circledR}$ primers and FAMMGB labeled probes (Additional file 1; Assays-onDemand $^{\mathbb{R}}$, Applied Biosystems) was conducted as previously described in detail [24].

\section{Plasma Cytokines/Chemokines, Glucose, Insulin, and Calcitriol}

Plasma cytokines/chemokines were measured according to manufacturer's instructions in duplicate for plasma samples $(20 \mu \mathrm{L} /$ reaction; $n=15 /$ group $)$ using a Milliplex ${ }^{B}$ MAP Mouse Cytokine/Chemokine Kit (Millipore) on a Bio-Plex system with $\mathrm{xMAP}^{\circledR}$ Lumine ${ }^{\circledR}$ technology utilizing Bio-Plex Manager version 5.0 software (Bio-Rad). Plasma glucose was measured according to manufacturer's instructions in duplicate $(5 \mu \mathrm{L} /$ reaction) with the Glucose (HK) Assay Kit (Sigma). Plasma insulin was measured according to manufacturer's instructions in duplicate $(5 \mu \mathrm{L} /$ reaction) with an Ultra Sensitive 
Mouse Insulin ELISA Kit (Crystal Chem). Plasma (100 $\mu \mathrm{L}$ pooled plasma from 3 mice/reaction) calcitriol levels ( $n=8-9$ /group) were measured by 1,25 -dihydroxyvitamin D radioimmunoassay (Immunodiagnostic Systems Inc.) according to manufacturer's instructions.

\section{Western Blot Analysis of Brown Adipose Tissue Uncoupling Protein 1 (UCP1)}

Whole intrascapular brown adipose tissue (BAT) pads ( $n=8$ /group) were homogenized in M-PER ${ }^{\circledR}$ Reagent (200 $\mu \mathrm{L} / 100 \mathrm{~g}$ tissue) in the presence of HALT Protease and Phosphatase Inhibitor Cocktail + $0.5 \mathrm{M}$ EDTA (Pierce). Proteins $(25 \mu \mathrm{g})$ were separated using a 12\% BisTris Criterion ${ }^{\mathrm{TM}}$ XT Precast Gel (Bio-Rad) and NuPAGE ${ }^{\circledR}$ MOPS SDS Running Buffer (Invitrogen) at $200 \mathrm{~V}$ for $\sim 1 \mathrm{~h}$. Proteins were transferred at $30 \mathrm{~V}$ for $1 \mathrm{~h}$ to an Immobilon $^{\mathrm{TM}}$ polyvinylidene fluoride membrane (Millipore), blocked overnight at $4{ }^{\circ} \mathrm{C}$ with $5 \%$ nonfat dry milk in PBS with $0.1 \%$ Tween 20 (PBS-T) and incubated with rabbit polyclonal anti-UCP1 primary antibody (1:5000 dilution; U6382, Sigma) at room temperature for $1 \mathrm{~h}$ followed by $3 \times 15$ min washes in PBS-T. The membrane was incubated with HRP-conjugated goat anti-mouse IgG secondary antibody (1:10000 dilution; 1031-05, Southern Biotech) at room temperature for $1 \mathrm{~h}$ followed by $3 \times 5-15 \mathrm{~min}$ washes in PBS-T. Antibody binding was visualized and relative protein levels were quantified using chemiluminescence (Immun-Star ${ }^{\mathrm{TM}}$ WesternC ${ }^{\mathrm{TM}}$ Chemiluminescent Kit, Bio-Rad) and ChemiDoc ${ }^{\mathrm{TM}}$ XRS + Imaging System (BioRad). Membrane was stripped using Restore ${ }^{\mathrm{TM}}$ PLUS Western Blot Stripping Buffer (Pierce) and reprobed using a pig monoclonal anti-glyceraldehyde-3-phosphate dehydrogenase (GAPDH) antibody (1:1000 dilution; NB300-221, Novus Biologicals) to control for protein loading.

\section{Liver Triglycerides}

Liver lipid extraction ( $n=10$ /group) was performed utilizing a modified Folch method [25]. Briefly, approximately $100 \mathrm{mg}$ of liver was homogenized in a 2:1 (v:v) chloroform:methanol solution $(20 \mu \mathrm{L} / \mathrm{mg}$ tissue) followed by separation of the organic phase and dehydration by speed-vac prior to being reconstituted in $1 \mathrm{~mL}$ isopropanol. Triglyceride content of lipid extracts was measured using an enzymatic assay kit (TR0100, Sigma) according to manufacture's instructions.

\section{Statistical Analysis}

A one-way ANOVA with Newman-Keuls Multiple Comparison post hoc test was used for three-group comparisons (Prism v. 4.0, Graphpad). Two-way repeated measures ANOVA was used to assess effects of diet, time, and diet $x$ time interactions on body weight gain and cumulative energy intake. Pearson's correlation coefficient was determined to assess bivariate relationships between body weight and CD68/CD11d mRNA abundance. In order to assess the contribution of differences in weight gain on markers of RP-WAT macrophage infiltration and inflammation, and to assess the impact of food intake on weight gain, ANCOVA was used to compare the group means of the log transformed outcome variables controlling for the indicated covariate (SAS for Windows Release 9.2). Data are expressed as mean \pm SEM and differences considered to be statistically significant at $P \leq 0.05$.

\section{Results}

\section{Body Weight Gain, Cumulative Energy Intake, and Feed Efficiency}

Body weight gain and terminal body weights were significantly reduced in mice fed high-Ca + NFDM relative to controls (Figure 1A). Contrary to our expectations, mice fed high-Ca were significantly heavier than controls (Figure 1A). There was a significant diet $\times$ time interaction on body weight gain $(P<0.0001)$. Compared to controls, mean body weight was heavier starting at d $27(P<0.05)$ and lower starting at d $36(P<0.01)$ of diet onward for mice fed high-Ca or high-Ca + NFDM, respectively. Mice fed high-Ca + NFDM weighed significantly less than mice fed high-Ca starting at d $17(P<0.05)$ of diet onward.

Increased cumulative energy intake in mice fed high- $\mathrm{Ca}$ compared to both controls and high-Ca + NFDM fed mice (Figure 1B) may account for increased body weight gain in this group, in contrast to high-Ca + NFDM mice that displayed greater cumulative energy intake compared to controls (Figure 1B) despite significantly lower body weight gain. Terminal body weights were not significantly different between mice fed high-Ca compared to controls when controlling for food intake (ANCOVA), indicating that intake explained much of the obesity in the high-Ca group; in contrast, when controlling for food intake, weight remained significantly reduced in mice fed high-Ca + NFDM compared to controls or mice fed high-Ca $(P<0.0001)$. There was a significant diet $\times$ time interaction on cumulative energy intake $(P<0.0001)$, with mean cumulative energy intake higher starting at $\mathrm{d} 13(P<0.05)$ and at $\mathrm{d} 57(P<$ 0.05 ) of diet onward for mice fed high-Ca or high-Ca + NFDM, respectively, compared to controls. Feed efficiency (mg weight gain $/ \mathrm{kJ}$ consumed) in mice fed high-Ca + NFDM was reduced $(2.3+0.1)$ compared to controls $(3.5 \pm 0.1 ; P<0.001)$ and high-Ca mice $(3.8 \pm 0.1 ; P<$ $0.001)$; the latter group had increased feed efficiency compared to controls $(P<0.01)$.

To determine the potential mechanisms underlying the marked differences in feed efficiencies, we examined markers of BAT activation considering the importance of this tissue to thermogenesis in mice. BAT weight was significantly increased in mice fed high-Ca compared to both controls and high-Ca + NFDM fed mice (Table 2). UCP1 protein content of BAT was increased to 1.7 fold of 


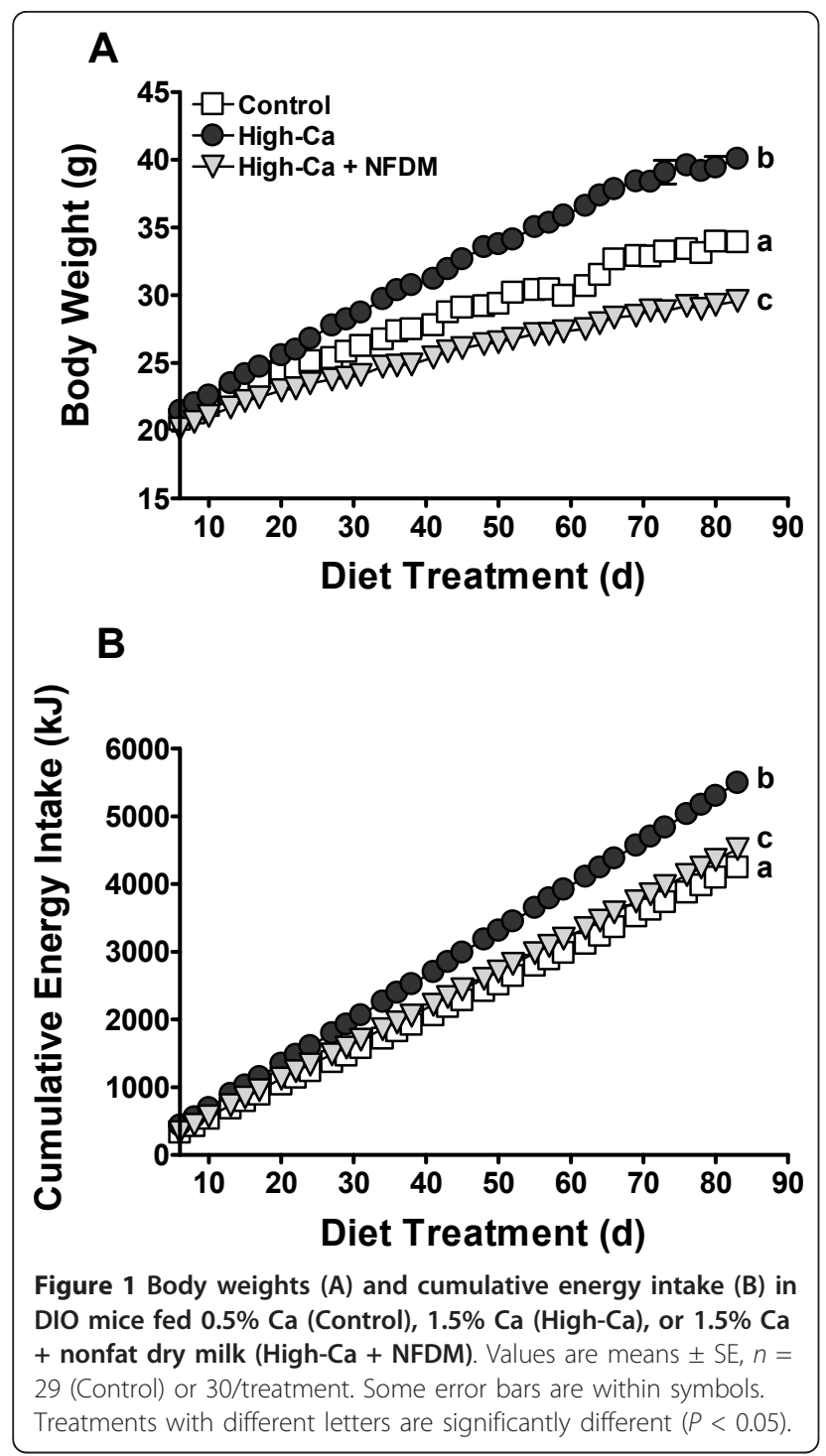

controls in mice fed high-Ca vs. the other groups (Additional file 2). Another factor potentially contributing to differences in feed efficiency is net energy absorption in the gut. There were significant diet-related differences in fecal output and fecal energy density (Additional file 3), and energy loss in the feces (as a \% of energy intake) was significantly decreased and increased in mice fed high-Ca and high-Ca + NFDM, respectively (Additional file 3). Increased energy consumption coupled to reduced fecal energy loss resulted in significantly increased net metabolizable energy (in kJ/d) in mice fed high-Ca $(66.2 \pm 1.8$; $P<0.001)$ compared to controls $(48.1 \pm 1.3)$ and high$\mathrm{Ca}+$ NFDM mice $(47.0 \pm 1.4)$.

\section{Body Composition and Metabolic Phenotypes}

Absolute weights of retroperitoneal (RP), epididymal (EPI), and subcutaneous (SC) fat pads were all significantly lower in mice fed high-Ca + NFDM compared to controls and mice fed high-Ca (Figure 2A), which was reflected in reduced total \% body fat (Figure 2B). Weights of EPI and $\mathrm{SC}$ fat pads were significantly heavier in high-Ca mice compared to controls (Figure 2A), but total \% body fat was not different between these groups (Figure 2B). Liver weights were significantly heavier in high-Ca mice compared to both controls and mice fed high-Ca + NFDM (Table 2); the latter two groups did not differ significantly. This corresponded to increased liver triglycerides $(\mathrm{mg} / \mathrm{g})$ in mice fed high-Ca $(98.4 \pm 16.5)$ compared to controls $(59.1 \pm 9.9 ; P<0.05)$ and high-Ca + NFDM mice $(28.1 \pm$ $10.1 ; P<0.01)$.

Mice fed high-Ca + NFDM had improved glucose tolerance (Figure 3A) with significantly reduced glucose area under the curve compared to controls and mice fed high$\mathrm{Ca}$ (Figure 3B). Postabsorptive plasma glucose concentrations $(\mathrm{mmol} / \mathrm{L})$ measured at the time of tissue collection was significantly higher in mice fed high-Ca $(20.6 \pm 0.6$; $P<0.001)$ and lower in high-Ca + NFDM fed mice (16.2 \pm $0.4 ; P<0.01)$, compared to controls $(18.2 \pm 0.4)$. Postabsorptive plasma insulin levels ( $\mathrm{pmol} / \mathrm{L}$ ) followed the same trend: significantly higher in mice fed high-Ca $(225.8 \pm$ 7.7; $P<0.001)$ and significantly lower in mice fed highCa + NFDM $(35.9 \pm 3.5 ; P<0.01)$ compared to controls $(100.3 \pm 7.75)$.

Dietary Ca-associated changes in expression of WAT fatty acid synthase (FAS) and interleukin 15 (IL-15) may regulate lipid accumulation, and shifts in uncoupling protein 2 (UCP2) could play a role in mitochondrial function and reactive oxygen species (ROS) generation [26]. FAS mRNA abundance in RP-WAT was not significantly different among diet treatment groups (Table 3); RP-WAT mRNA abundance of UCP2 was significantly decreased in mice fed high-Ca and high-Ca + NFDM fed mice compared to controls (Table 3), and this reduction was greater in mice fed high-Ca. mRNA abundance of IL-15 in RPWAT was significantly decreased in mice fed high-Ca compared to controls (Table 3). IL-15 mRNA expression does not necessarily coincide with protein secretion [27] and skeletal muscle is the major site of IL-15 mRNA transcription and probably secretion $[28,29]$. We noted that plasma IL-15 levels were increased, although highly variable and not statistically significant, in mice fed high-Ca + NFDM compared to both controls and mice fed high-Ca (Table 4).

\section{Inflammatory Phenotypes and Plasma Calcitriol}

A suite of genes typically associated with obesityinduced WAT macrophage infiltration, inflammation, and hypoxic stress were surveyed to determine if dietary $\mathrm{Ca}$ or dairy reduce these parameters in DIO mice. We have previously measured this panel of markers and found them to be sensitive to DIO in this model [24]. 
Table 2 Tissue weights in diet induced obese mice fed $0.5 \% \mathrm{Ca}$ (Control), $1.5 \% \mathrm{Ca}$ (High-Ca), or $1.5 \% \mathrm{Ca}+$ nonfat dry milk (High-Ca + NFDM) ${ }^{1}$

\begin{tabular}{llll}
\hline & & Diet \\
\hline Tissue & Control & High-Ca & High-Ca + NFDM \\
\hline Liver (g) & $1.2 \pm 0.03^{\mathrm{a}}$ & $1.7 \pm 0.07^{\mathrm{b}}$ & $1.1 \pm 0.02^{\mathrm{a}, \mathrm{c}}$ \\
Liver (\% body weight) & $3.5 \pm 0.05^{\mathrm{a}}$ & $4.1 \pm 0.12^{\mathrm{b}}$ & $3.7 \pm 0.06^{\mathrm{a}} \mathrm{c}$ \\
Gastrocnemius muscles (mg) & $301 \pm 3.6^{\mathrm{a}}$ & $311 \pm 4.2^{\mathrm{b}}$ & $288 \pm 2.9^{\mathrm{c}}$ \\
Gastrocnemius muscles (\% body weight) & $0.9+0.01^{\mathrm{a}}$ & $0.8 \pm 0.02^{\mathrm{b}}$ & $1.0 \pm 0.01^{\mathrm{c}}$ \\
Brown adipose tissue (mg) & $176 \pm 8.3^{\mathrm{a}}$ & $299 \pm 12.1^{\mathrm{b}}$ & $98 \pm 4.1^{\mathrm{c}}$ \\
Brown adipose tissue (\% body weight) & $0.5 \pm 0.02^{\mathrm{a}}$ & $0.7 \pm 0.02^{\mathrm{b}}$ & $0.3 \pm 0.01^{\mathrm{c}}$ \\
Spleen (mg) & $73 \pm 1.6^{\mathrm{a}}$ & $86 \pm 2.5^{\mathrm{b}}$ & $66 \pm 1.8^{\mathrm{c}}$ \\
Spleen (\% body weight) & $0.2 \pm 0.00$ & $0.2 \pm 0.01$ & $0.2 \pm 0.01$ \\
\hline
\end{tabular}

Values are means $+\mathrm{SE}, n=29$ or 30 . Values with different superscript letter are significantly different $(P<0.05)$.

RP-WAT mRNA abundance of the macrophage specific surface antigen CD68 was increased to $\sim 200 \%$ and decreased to $\sim 71 \%$ of control values in mice fed high-Ca and high-Ca + NFDM fed mice, respectively (Table 3 ). We have previously shown CD11d (leukocyte exclusive

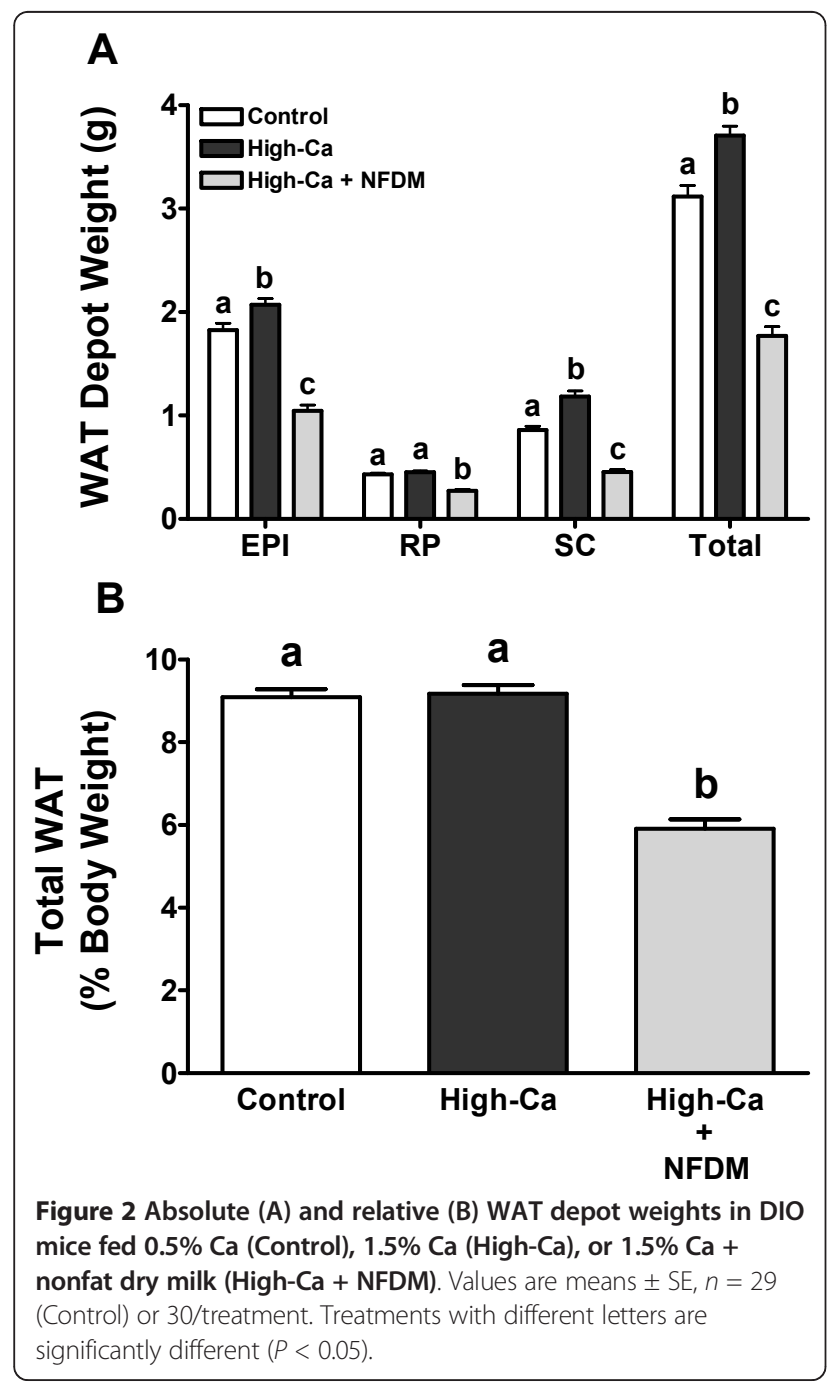

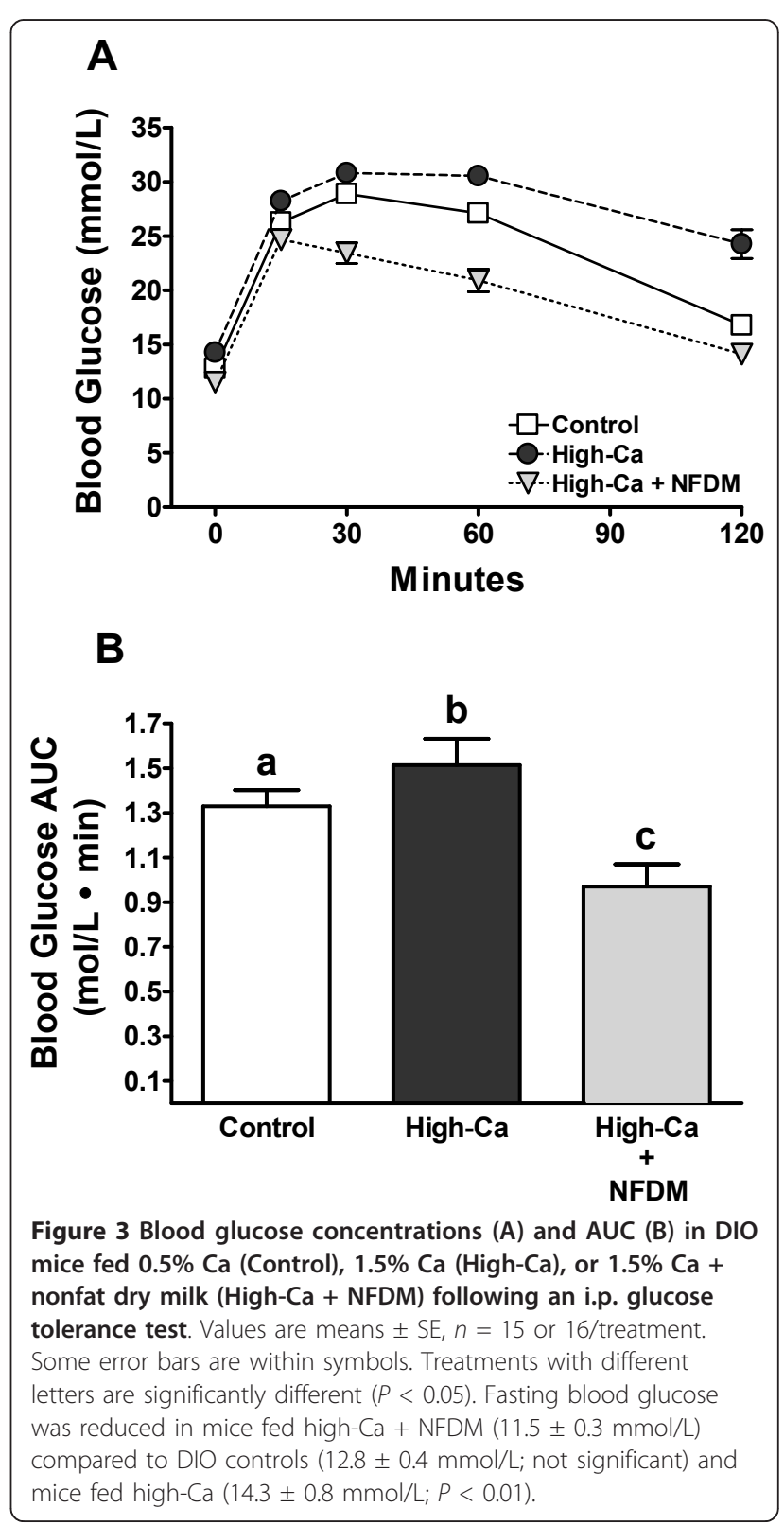


Table 3 RP-WAT mRNA levels in diet induced obese mice fed $0.5 \% \mathrm{Ca}$ (Control), $1.5 \% \mathrm{Ca}$ (High-Ca), or $1.5 \% \mathrm{Ca}+$ nonfat dry milk (High-Ca + NFDM) ${ }^{1}$

\begin{tabular}{llll}
\hline & \multicolumn{3}{c}{ Diet } \\
\hline Gene & Control & $\begin{array}{c}\text { High-Ca } \\
\% \text { of Control }\end{array}$ \\
\hline Cd68 & $100.0 \pm 8.3^{\mathrm{a}}$ & $213.1 \pm 19.5^{\mathrm{b}}$ & $70.9 \pm 15.5^{\mathrm{a}}$ \\
Itgad (CD11d) & $100.0 \pm 13.1^{\mathrm{a}}$ & $234.7 \pm 28.5^{\mathrm{b}}$ & $8.7 \pm 2.5^{\mathrm{c}}$ \\
CCI2 (MCP-1) & $100.0 \pm 9.2^{\mathrm{a}}$ & $156.2 \pm 9.0^{\mathrm{b}}$ & $43.6 \pm 4.7^{\mathrm{c}}$ \\
Tnf (TNF $\alpha)$ & $100.0 \pm 4.3^{\mathrm{a}}$ & $154.3 \pm 10.5^{\mathrm{b}}$ & $65.4 \pm 8.2^{\mathrm{c}}$ \\
II6 & $100.0 \pm 5.2^{\mathrm{a}}$ & $127.1 \pm 10.2^{\mathrm{b}}$ & $75.7 \pm 4.7^{\mathrm{c}}$ \\
Hif1a (HIF-1 $\alpha)$ & $100.0 \pm 8.0^{\mathrm{a}}$ & $82.3 \pm 4.1^{\mathrm{b}}$ & $51.2 \pm 3.0^{\mathrm{c}}$ \\
II10 & $100.0 \pm 9.0^{\mathrm{a}}$ & $263.6 \pm 29.9^{\mathrm{b}}$ & $97.0 \pm 16.2^{\mathrm{a}}$ \\
Retnla (FIZZ-1) & $100.0 \pm 5.2^{\mathrm{a}}$ & $174.9 \pm 16.3^{\mathrm{b}}$ & $78.9 \pm 7.9^{\mathrm{a}}$ \\
Calca (CGRP $\alpha)$ & $100.0 \pm 15.3$ & $75.5 \pm 6.7$ & $102.5 \pm 13.8$ \\
II15 & $100.0 \pm 3.4^{\mathrm{a}}$ & $68.7 \pm 8.4^{\mathrm{b}}$ & $94.6 \pm 7.2^{\mathrm{a}}$ \\
Fas & $100.0 \pm 2.8$ & $112.1 \pm 4.7$ & $105.1 \pm 4.1$ \\
Ucp2 & $100.0 \pm 6.0^{\mathrm{a}}$ & $55.5 \pm 4.4^{\mathrm{b}}$ & $81.9 \pm 4.6^{\mathrm{c}}$ \\
\hline
\end{tabular}

${ }^{1}$ Values are means $+\mathrm{SE}, n=29$ or 30 . Values with different superscript letter are significantly different $(P<0.05)$.

integrin $\alpha_{\mathrm{D}} \beta_{2}$ ) RP-WAT mRNA abundance was markedly increased obese mice relative to non-obese controls [24], and this parameter was increased to $\sim 235 \%$ and decreased to $\sim 9 \%$ of control values in high-Ca and high$\mathrm{Ca}+$ NFDM fed mice, respectively (Table 2). Inflammatory markers associated with obese WAT (monocyte chemoattractant protein 1, MCP-1; tumor necrosis factor $\alpha$, TNFa; IL-6) displayed significantly increased and decreased mRNA abundances in RP-WAT of mice fed high-Ca and high-Ca + NFDM, respectively, compared to controls (Table 3). However, hypoxia inducible factor $1 \alpha$ (HIF-1 $\alpha$ ) mRNA abundance in RP-WAT was significantly decreased in mice fed high-Ca or high-Ca + NFDM compared to controls (Table 3). RP-WAT mRNA abundance of IL-10, an anti-inflammatory cytokine, and found in inflammatory zone 1 (FIZZ-1), a marker of alternatively activated macrophages, were significantly increased in mice fed high-Ca compared to both controls

Table 4 Plasma cytokines in diet induced obese mice fed $0.5 \% \mathrm{Ca}$ (Control), $1.5 \% \mathrm{Ca}$ (High-Ca), or $1.5 \% \mathrm{Ca}+$ nonfat dry milk (High-Ca + NFDM) ${ }^{1}$

\begin{tabular}{llll}
\hline & \multicolumn{3}{c}{ Diet } \\
\hline Cytokine & Control & High-Ca & High-Ca + NFDM \\
& \multicolumn{3}{c}{$\mathbf{n g} / \mathbf{L}$} \\
\hline IL-6 & $2.7 \pm 0.5$ & $4.1 \pm 1.1$ & $1.6 \pm 0.3^{*}$ \\
IL-10 & $3.7 \pm 3.3$ & $6.4 \pm 4.4$ & $3.9 \pm 2.5$ \\
IL-12(p70) & $4.3 \pm 1.7$ & $12.9 \pm 4.2$ & $7.9 \pm 4.5$ \\
MCP-1 & $16.1 \pm 2.5$ & $16.1 \pm 3.7$ & $9.6 \pm 3.9$ \\
TNF $\alpha$ & $3.2 \pm 0.2$ & $3.0 \pm 0.2$ & $3.8 \pm 0.9$ \\
IL-15 & $38.6 \pm 6.2$ & $48.2 \pm 11.4$ & $70.8 \pm 22.7$ \\
\hline
\end{tabular}

${ }^{1}$ Values are means $+\mathrm{SE}, n=15$. ${ }^{*} \mathrm{P}<0.05$ compared to mice fed high-Ca. and high-Ca + NFDM fed mice (Table 3). Macrophagederived inflammatory cytokines have previously been shown to increase calcitonin gene related peptide $\alpha$ (CGRP $\alpha$ ) expression in adipocytes and CGRP $\alpha$ may have anti-inflammatory effects on macrophages [30,31]. This target is also regulated in neurons and thyroid cells by $\mathrm{Ca}$ status and calcitriol $[32,33]$. However, RP-WAT mRNA abundance of CGRP $\alpha$ was not different between diet treatment groups (Table 3). Despite differences in visceral WAT inflammatory gene expression, differences in plasma markers associated with inflammation were less apparent and highly variable (Table 4 ).

Previous observations that high dietary Ca both with and without dairy reduce WAT inflammatory gene expression were confounded by $\mathrm{Ca} /$ dairy-associated reductions in body weight and adiposity $[20,21]$. To illustrate the relative influence of body weight on WAT macrophage accumulation, correlations between body weight and macrophage marker mRNA levels were examined (Figure 4). There were significant positive correlations between body weight and the mRNA expression of CD68 and CD11d in RP-WAT of DIO mice, regardless of diet treatment, and across a broad range of body weights (Figure 4). Controlling for body weight as a covariate, treatment differences in WAT CD68 mRNA abundances were not significantly different indicating that CD68-positive macrophage numbers in WAT are closely yoked to body weight. Controlling for weight and food intake, differences in CD11d mRNA abundance comparing controls and high-Ca mice were not statistically significant, but the reduction in CD11d expression in mice fed high-Ca + NFDM remained highly significant $(P<0.0001)$. RP-WAT mRNA abundances of other inflammatory markers (see Table 3) were not significantly different among diet treatment groups when controlling for body weight, with the exceptions of MCP-1 and HIF- $1 \alpha$ : MCP-1 remained significantly decreased in high-Ca + NFDM mice compared to controls $(P<0.001)$ or high-Ca mice $(P<$ 0.01 ), and HIF- $1 \alpha$ remained significantly decreased in mice fed both of the high-Ca diets compared to controls $(P<0.01)$.

Calcitriol stimulates inflammatory responses in cultured adipocytes and macrophages [19], and dietary $\mathrm{Ca}$ suppression of circulating calcitriol was observed concurrent with reduced WAT inflammation associated with obesity development $[20,21]$. Plasma calcitriol (pmol/L) was significantly reduced in mice fed high-Ca $(123.9 \pm 13.0)$ compared to controls $(187.1 \pm 8.6 ; P<$ $0.01)$ and high-Ca + NFDM fed mice $(168.9 \pm 16.6 ; P<$ $0.05)$, but this was not associated with reductions in adiposity and inflammation. The more modest reduction in plasma calcitriol in mice fed high-Ca + NFDM was not significantly different compared to controls. 


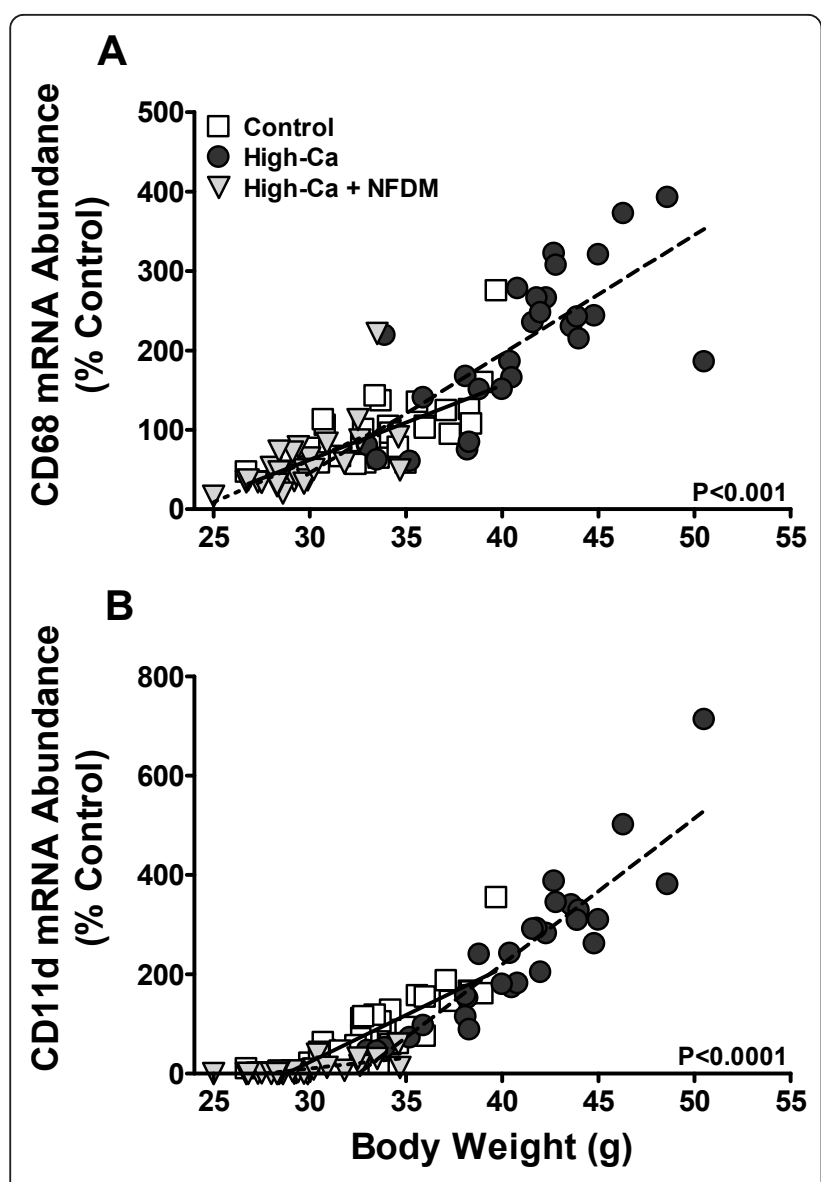

Figure 4 Relative mRNA levels of CD68 (A) and CD11d (B) in RPWAT are significantly correlated to body weight in DIO mice fed $0.5 \%$ Ca (Controls, $r=0.62$ ), $1.5 \%$ Ca (High-Ca; $r=0.76$ ), or $1.5 \%$ $\mathrm{Ca}+$ nonfat dry milk (High-Ca + NFDM; $r=0.63$ ), $n=29$ (Control) or 30/treatment. P-values apply to all correlations within each panel.

\section{Discussion}

Consistent with previous reports $[4,6,7,9]$, we showed reduced body weight and adiposity upon feeding a NFDM diet containing high $\mathrm{Ca}$ to high fat fed polygenic DIO rodents. Reductions in body weight and adiposity were accompanied by lower WAT inflammation and liver triglycerides as well as improved glucose tolerance. However, the data do not support the idea that high dietary $\mathrm{Ca}$ in isolation provides protection against obesity and associated inflammation since DIO mice fed a soy protein-based high-Ca diet actually became more obese and displayed higher WAT inflammation, compared to lower-Ca controls or mice fed high-Ca in a NFDM matrix. This differs from observations in high-Ca fed aP2-agouti transgenic mice fed an obesity-promoting diet where increased dietary $\mathrm{Ca}$ attenuated weight gain, adiposity, and WAT inflammation $[5,20,21,34]$. Experimental variables that may have contributed to these discrepancies include diet composition, energy consumption, genetic variation, and study duration.
In the present study, body weight gain was not significantly different between control mice and mice fed high-Ca when controlling for energy consumption as a covariate. Thus, increased energy consumption can explain differences in body weight gain between these diet treatment groups, whereas daily food intake was not different in aP2agouti transgenic mice fed an obesigenic diet containing high $\mathrm{Ca}[5,20,21,34]$. Similar to our results, $21 \mathrm{wk}$ food consumption was increased in DIO male C57BL/6J mice fed high $\mathrm{Ca}$ in the context of a high fat diet $(60 \% \mathrm{kcal}$ as fat) containing whey, and a modest non-significant increase was observed in DIO mice fed a high $\mathrm{Ca}$, casein-based diet [6]. Mice fed a 43\% fat, NFDM-based high-Ca diet did not display a difference in energy intake relative to low $\mathrm{Ca}$, casein controls [7]. Thus, results in polygenic DIO mouse models are consistent in that animals fed a high-Ca diet containing NFDM or whey protein display reduced body weight gain and adiposity despite increased or unchanged energy intakes. Protein source, and not Ca level, primarily contributed to body composition differences in DIO rats fed differing levels of $\mathrm{Ca}$ in the context of different dairy protein sources (NFDM, whey, or casein) [35]. These observations indicate that non-Ca components derived from dairy mainly drive adiposity reduction in polygenic DIO rodents.

Suppression of circulating calcitriol via increased $\mathrm{Ca}$ intake has been proposed as a primary mechanism for the anti-obesity and anti-inflammatory properties of high dietary $\mathrm{Ca}$ [22]. There is evidence that mice lacking the nuclear vitamin D receptor or enzyme required to generate calcitriol have reduced adiposity, lower serum leptin, and increased food intake [36]. Reduced adiposity in aP2agouti transgenic mice fed obesigenic high-Ca diets was associated with reductions in blood calcitriol [20,21]. However, we observed that adiposity and body weight outcomes in DIO mice fed high-Ca in isolation and in high$\mathrm{Ca}+$ NFDM showed no relation to differences in plasma calcitriol, indicating that changes in calcitriol are not sufficient to explain differences in body weight and adiposity in this model.

Mice that consumed high-Ca in a soy protein-based diet demonstrated increased feed efficiency, in contrast to a lower feed efficiency in mice fed high-Ca + NFDM. These results could emanate from diet-related differences in gut energy uptake and/or tissue thermogenesis. There was in fact increased net uptake of energy across the gut in mice fed the soy-based high-Ca diet. An observed increase in fecal energy loss in high-Ca + NFDM fed mice cannot explain their reduced feed efficiency, since increased energy intake in this group negated any difference in metabolizable energy compared to controls. With respect to thermogenesis, reduced feed efficiency in mice fed high-Ca + NFDM was not accompanied by increased BAT UCP1 protein expression. Since UCP1 expression is 
a surrogate for BAT thermogenic activation, one interpretation is that in the high-Ca + NFDM mice enhanced BAT thermogenesis did not contribute to the anti-obesity effects of this diet. Alternatively, BAT UCP1 expression was maintained at control levels despite lower body weight in the high-Ca + NFDM mice, so another interpretation is that this diet resulted in relative retention of BAT thermogenic potential. The increased BAT size and UCP1 protein expression in obese mice fed high-Ca was reminiscent of that seen in cafeteria fed rats [37], and this might be explained teleologically as a physiological adaptation to overnutrition. Additional studies of thermogenesis-related pathways in muscle and other tissues are warranted to clarify the mechanisms underpinning reduced feed efficiency in high-Ca + NFDM fed mice. The influence of calcitriol on WAT and muscle expression of IL-15 has been proposed to alter energy metabolism, with expression increased upon feeding high-Ca $[20,26]$. Increased IL-15 secretion has also been hypothesized to discourage lipid accumulation [20,38]. In our studies, WAT IL-15 gene expression was actually decreased in mice fed high-Ca compared to controls (a relationship held constant even after controlling body weight gain), and there were no significant differences in plasma IL-15 across diets. Thus, in polygenic DIO mice, differences in adiposity and feed efficiency were not associated with diet-related changes in WAT IL-15 expression or circulating IL-15 concentrations.

Non-Ca bioactive components of dairy thought to contribute to the anti-obesity effects of NFDM may be derived primarily from the whey protein fraction [22]. Supplementation with whey protein isolate reduced adiposity and increased energy expenditure in high fat fed mice [39]. Whey protein is a rich dietary source of branched chain amino acids (BCAA), which could in theory contribute to activation of thermogenesis. Leucine or whey protein isolate supplementation of drinking water increased energy expenditure and reduced diet induced obesity in mice without reducing energy intake $[39,40]$. Leucine when provided to muscle cell cultures increased energy consumption and indices of mitochondrial biogenesis (e.g., PGC-1 expression, mitochondrial mass), hypothesized to result from activation of mammalian target of rapamycin complex 1 (mTORC1) [41,42] or indirectly through anaplerosis [43]. Whether BCAA derived from the NFDM diet contributes to metabolic outcomes requires further experimental validation. Notably, milk proteins also possess bioactive peptides that have ACE-inhibitory properties [44], and the ACE product angiotensin II enhances adipocyte lipid storage, promotes inflammation via activation of the $\mathrm{NF} \kappa \mathrm{B}$ pathway, and stimulates ROS-mediated insulin resistance [45].

Chronic inflammation of WAT, hallmarked by macrophage accumulation, contributes to obesity-associated morbidities. Since calcitriol evokes a pro-inflammatory response in both adipocytes and macrophages, and enhances pro-inflammatory mediators in co-cultures of both cell types in vitro [19], high dietary Ca suppression of plasma calcitriol may have anti-inflammatory properties [20]. High dietary Ca both with and without dairy reduced WAT and systemic inflammation compared to low dietary $\mathrm{Ca}$ in aP2-agouti transgenic obese mice [21]. However, interpretations of these observations are confounded by reduced adiposity resulting from high dietary $\mathrm{Ca}$ intake in that model. We found that WAT expression of the pan-macrophage surface antigen CD68 correlated positively with body weight regardless of diet. WAT mRNA abundance for CD11d (an immune cell-specific cell adhesion molecule expressed on a subset of macrophages [46]) also correlated with body weight, but for any given weight was lower in NDFM-fed mice compared to controls or high-Ca fed mice. Diet-associated differences in most WAT inflammatory gene markers were lost when controlling for body weight. These results conclusively demonstrate that dietary $\mathrm{Ca}$ and/or NFDM effects on WAT inflammation in DIO mice are primarily explained by their impact on weight. In DIO mice fed different levels of fat $(10 \%, 45 \%$, and $60 \%)$, WAT macrophage marker expression correlated with body weight and adiposity in lean-to-moderately obese animals [24], similar to our current observations. These findings support the hypothesis that WAT macrophage infiltration (at least for some macrophage sub-types) is closely yoked to expansion of energy storage capacity during modest caloric overnutrition, possibly as a mechanism for macrophage-mediated WAT extracellular matrix and vascular remodeling to accommodate normal physiologic adipocyte hypertrophy. Significant correlations between WAT inflammatory markers and body weight was reported when looking across disparate mouse obesity models [15], and positive correlations were observed between \% CD14+ cells in isolated stromal vascular cells from WAT and BMI in normal weight to obese humans $[47,48]$. Shaul et al. [49] have also considered a remodeling function based on dynamic M2-like macrophage phenotypes in rodents. The observations that WAT macrophage marker expression closely tracks body weight (at least in lean to moderate obese states) highlights a need to understand weight-specific immune signals and macrophage functions during normal, non-pathological WAT expansion and contraction.

\section{Conclusion}

Mechanisms underlying the anti-obesity and/or antiinflammatory properties of dairy components remain to be clarified. A primary role for increased dietary $\mathrm{Ca}$ is not supported in the current DIO mouse model since high $\mathrm{Ca}$ fed in a soy protein-based diet did not reduce, 
and in fact increased, obesity and associated adipose inflammation in stark contrast to animals fed high $\mathrm{Ca}$ in a NFDM-based matrix. Further deconvolution of the complex components of dairy foods is required in order to identify those specific factors that influence energy balance and inflammation.

\section{Additional material}

Additional file 1: Quantitative PCR primer-probe information for metabolic and inflammatory gene targets.

Additional file 2: Brown adipose tissue (BAT) protein content of uncoupling protein 1 (UCP1) in DIO mice fed $0.5 \% \mathrm{Ca}$ (Control), $1.5 \% \mathrm{Ca}$ (High-Ca), or $1.5 \% \mathrm{Ca}+$ nonfat dry milk (High-Ca + NFDM). Values are means $+\mathrm{SE}, \mathrm{n}=8$ /treatment (arbitrary densitometry units). Treatments with different letters are significantly different $(P<0.05)$. UCP1 protein expression is normalized to glyceraldehyde 3-phosphate dehydrogenase (GAPDH) protein expression. Photo shows a

representative Western blot result.

Additional file 3: Fecal weight (A), energy (B), and energy loss (C) in DIO mice fed $0.5 \% \mathrm{Ca}$ (Control), $1.5 \% \mathrm{Ca}$ (High-Ca), or $1.5 \% \mathrm{Ca}+$ nonfat dry milk (High-Ca + NFDM). Values are means $+\mathrm{SE}, \mathrm{n}=10 /$ treatment. Treatments with different letters are significantly different $(P<0.05)$.

\section{Abbreviations}

ACE: angiotensin converting enzyme; BAT: brown adipose tissue; BCAA: branched chain amino acids; Ca: calcium; CGRP: calcitonin gene related peptide; DIO: diet-induced obese; FAS: fatty acid synthase; FIZZ: found in inflammatory zone; EPI: epididymal; HIF: hypoxia inducible factor; IL: interleukin; MCP: monocyte chemoattractant protein; NFDM: nonfat dry milk; ROS: reactive oxygen species; RP: retroperitoneal; SC: subcutaneous; TNF: tumor necrosis factor; UCP: uncoupling protein; WAT: white adipose tissue.

\section{Acknowledgements}

The authors would like to thank Dr. Trina Knotts for guidance and technical assistance with Western blot analyses and quantification of liver triglycerides, Jan Peerson for statistical analysis, and the UC Davis vivarium staff in helping care for the animals. Supported in part by intramural USDA-ARS Projects 5306-51530-016-00D and 5306-51530-019-00 and the National Dairy Council (grant administered by the Dairy Research Institute). USDA is an equal opportunity provider and employer.

\section{Author details}

'Department of Nutrition, University of California, One Shields Avenue, Davis, CA, USA. ${ }^{2}$ Department of Animal Science, University of California, One Shields Ave., Davis, CA 95616, USA. ${ }^{3}$ Obesity \& Metabolism Research Unit, United States Department of Agriculture-Agricultural Research Service Western Human Nutrition Research Center, 430 W. Health Sciences Dr., Davis, CA 95616, USA.

\section{Authors' contributions}

All authors edited the manuscript, and read and approved the final version of the paper. APT and TND were jointly responsible for conducting the studies and sample assays. APT and SHA were primarily responsible for writing, JBD and PJO assisted with sample processing and data analysis.

\section{Competing interests}

The authors declare that they have no competing interests.

Received: 18 November 2011 Accepted: 23 January 2012 Published: 23 January 2012

\section{References}

1. Zemel MB: The role of dairy foods in weight management. J Am Coll Nutr 2005, 24:537S-546S.
2. Van Loan M: The role of dairy foods and dietary calcium in weight management. J Am Coll Nutr 2009, 28(Suppl 1):120S-129S.

3. Lanou AJ, Barnard ND: Dairy and weight loss hypothesis: an evaluation of the clinical trials. Nutr Rev 2008, 66:272-279.

4. Papakonstantinou E, Flatt WP, Huth PJ, Harris RB: High dietary calcium reduces body fat content, digestibility of fat, and serum vitamin $D$ in rats. Obes Res 2003, 11:387-394.

5. Sun X, Zemel MB: Calcium and dairy products inhibit weight and fat regain during ad libitum consumption following energy restriction in Ap2-agouti transgenic mice. J Nutr 2004, 134:3054-3060.

6. Pilvi TK, Korpela R, Huttunen M, Vapaatalo H, Mervaala EM: High-calcium diet with whey protein attenuates body-weight gain in high-fat-fed C57BI/6J mice. Br J Nutr 2007, 98:900-907.

7. Parra P, Bruni G, Palou A, Serra F: Dietary calcium attenuation of body fat gain during high-fat feeding in mice. J Nutr Biochem 2008, 19:109-117.

8. Christensen R, Lorenzen JK, Svith CR, Bartels EM, Melanson EL, Saris WH, Tremblay A, Astrup A: Effect of calcium from dairy and dietary supplements on faecal fat excretion: a meta-analysis of randomized controlled trials. Obes Rev 2009, 10:475-486.

9. Zemel MB, Shi H, Greer B, Dirienzo D, Zemel PC: Regulation of adiposity by dietary calcium. Faseb J 2000, 14:1132-1138.

10. Shi H, Norman AW, Okamura WH, Sen A, Zemel MB: 1alpha,25Dihydroxyvitamin D3 modulates human adipocyte metabolism via nongenomic action. Faseb J 2001, 15:2751-2753.

11. Zemel MB: Regulation of adiposity and obesity risk by dietary calcium: mechanisms and implications. J Am Coll Nutr 2002, 21:146S-151S.

12. Olefsky JM, Glass CK: Macrophages, inflammation, and insulin resistance. Annu Rev Physiol 72:219-246.

13. Fernandez-Veledo S, Nieto-Vazquez I, Vila-Bedmar R, Garcia-Guerra L, Alonso-Chamorro M, Lorenzo M: Molecular mechanisms involved in obesity-associated insulin resistance: therapeutical approach. Arch Physiol Biochem 2009, 115:227-239.

14. Zeyda M, Stulnig TM: Obesity, inflammation, and insulin resistance-a mini-review. Gerontology 2009, 55:379-386.

15. Weisberg SP, McCann D, Desai M, Rosenbaum M, Leibel RL, Ferrante AW Jr: Obesity is associated with macrophage accumulation in adipose tissue. J Clin Invest 2003, 112:1796-1808.

16. Xu H, Barnes GT, Yang Q, Tan G, Yang D, Chou CJ, Sole J, Nichols A, Ross JS, Tartaglia LA, Chen H: Chronic inflammation in fat plays a crucial role in the development of obesity-related insulin resistance. J Clin Invest 2003, 112:1821-1830

17. Fain JN: Release of interleukins and other inflammatory cytokines by human adipose tissue is enhanced in obesity and primarily due to the nonfat cells. Vitam Horm 2006, 74:443-477.

18. Zeyda M, Farmer D, Todoric J, Aszmann O, Speiser M, Gyori G, Zlabinger GJ, Stulnig TM: Human adipose tissue macrophages are of an antiinflammatory phenotype but capable of excessive pro-inflammatory mediator production. Int J Obes (Lond) 2007, 31:1420-1428.

19. Sun $X$, Zemel MB: Calcitriol and calcium regulate cytokine production and adipocyte-macrophage cross-talk. J Nutr Biochem 2008, 19:392-399.

20. Sun X, Zemel MB: Calcium and 1,25-dihydroxyvitamin D3 regulation of adipokine expression. Obesity (Silver Spring) 2007, 15:340-348.

21. Zemel MB, Sun $X$ : Dietary calcium and dairy products modulate oxidative and inflammatory stress in mice and humans. J Nutr 2008, 138:1047-1052

22. Zemel MB: Proposed role of calcium and dairy food components in weight management and metabolic health. Phys Sportsmed 2009, 37:29-39.

23. Surwit RS, Kuhn CM, Cochrane C, McCubbin JA, Feinglos MN: Diet-induced type II diabetes in C57BL/6J mice. Diabetes 1988, 37:1 163-1167.

24. Thomas AP, Dunn TN, Oort PJ, Grino M, Adams SH: Inflammatory Phenotyping Identifies CD11d as a Gene Markedly Induced in White Adipose Tissue in Obese Rodents and Women. J Nutr 2011, 141:1172-1180

25. Folch J, Lees M, Sloane Stanley GH: A simple method for the isolation and purification of total lipides from animal tissues. J Biol Chem 1957, 226:497-509.

26. Zemel MB, Sun X: Calcitriol and energy metabolism. Nutr Rev 2008, 66: S139-146.

27. Tagaya Y, Bamford RN, DeFilippis AP, Waldmann TA: IL-15: a pleiotropic cytokine with diverse receptor/signaling pathways whose expression is controlled at multiple levels. Immunity 1996, 4:329-336. 
28. Grabstein KH, Eisenman J, Shanebeck K, Rauch C, Srinivasan S, Fung V, Beers C, Richardson J, Schoenborn MA, Ahdieh M, et al: Cloning of a T cell growth factor that interacts with the beta chain of the interleukin-2 receptor. Science 1994, 264:965-968.

29. Tagaya Y, Kurys G, Thies TA, Losi JM, Azimi N, Hanover JA, Bamford RN, Waldmann TA: Generation of secretable and nonsecretable interleukin 15 isoforms through alternate usage of signal peptides. Proc Natl Acad Sci USA 1997, 94:14444-14449.

30. Nong YH, Titus RG, Ribeiro JM, Remold HG: Peptides encoded by the calcitonin gene inhibit macrophage function. J Immunol 1989, 143:45-49.

31. Gomes RN, Castro-Faria-Neto HC, Bozza PT, Soares MB, Shoemaker CB, David JR, Bozza MT: Calcitonin gene-related peptide inhibits local acute inflammation and protects mice against lethal endotoxemia. Shock 2005, 24:590-594.

32. Cote GJ, Rogers DG, Huang ES, Gagel RF: The effect of 1,25dihydroxyvitamin D3 treatment on calcitonin and calcitonin generelated peptide mRNA levels in cultured human thyroid C-cells. Biochem Biophys Res Commun 1987, 149:239-243.

33. DiPette DJ, Westlund KN, Holland OB: Dietary calcium modulates spinal cord content of calcitonin gene-related peptide in the rat. Neurosci Lett 1988, 95:335-340.

34. Sun $X$, Zemel MB: Dietary calcium regulates ROS production in aP2agouti transgenic mice on high-fat/high-sucrose diets. Int J Obes (Lond) 2006, 30:1341-1346.

35. Eller LK, Reimer RA: Dairy protein attenuates weight gain in obese rats better than whey or casein alone. Obesity (Silver Spring) 18:704-711.

36. Narvaez CJ, Matthews D, Broun E, Chan M, Welsh J: Lean phenotype and resistance to diet-induced obesity in vitamin $D$ receptor knockout mice correlates with induction of uncoupling protein-1 in white adipose tissue. Endocrinology 2009, 150:651-661.

37. Roca P, Rodriguez AM, Oliver P, Bonet ML, Quevedo S, Pico C, Palou A: Brown adipose tissue response to cafeteria diet-feeding involves induction of the UCP2 gene and is impaired in female rats as compared to males. Pflugers Arch 1999, 438:628-634.

38. Quinn LS: Interleukin-15: a muscle-derived cytokine regulating fat-to-lean body composition. J Anim Sci 2008, 86:E75-83.

39. Shertzer HG, Woods SE, Krishan M, Genter MB, Pearson KJ: Dietary whey protein lowers the risk for metabolic disease in mice fed a high-fat diet. J Nutr 2011, 141:582-587.

40. Zhang Y, Guo K, LeBlanc RE, Loh D, Schwartz GJ, Yu YH: Increasing dietary leucine intake reduces diet-induced obesity and improves glucose and cholesterol metabolism in mice via multimechanisms. Diabetes 2007, 56:1647-1654.

41. Sun $X$, Zemel MB: Leucine modulation of mitochondrial mass and oxygen consumption in skeletal muscle cells and adipocytes. Nutr Metab (Lond) 2009, 6:26.

42. Cunningham JT, Rodgers JT, Arlow DH, Vazquez F, Mootha VK, Puigserver P: mTOR controls mitochondrial oxidative function through a YY1-PGC1alpha transcriptional complex. Nature 2007, 450:736-740.

43. Owen OE, Kalhan SC, Hanson RW: The key role of anaplerosis and cataplerosis for citric acid cycle function. J Biol Chem 2002, 277:30409-30412.

44. Saito T: Antihypertensive peptides derived from bovine casein and whey proteins. Adv Exp Med Biol 2008, 606:295-317.

45. Yvan-Charvet $L$, Quignard-Boulange A: Role of adipose tissue reninangiotensin system in metabolic and inflammatory diseases associated with obesity. Kidney Int 2011, 79:162-168.

46. Gahmberg CG, Valmu L, Fagerholm S, Kotovuori P, Ihanus E, Tian L, PessaMorikawa T: Leukocyte integrins and inflammation. Cell Mol Life Sci 1998 54:549-555.

47. Curat CA, Miranville A, Sengenes C, Diehl M, Tonus C, Busse R, Bouloumie A: From blood monocytes to adipose tissue-resident macrophages: induction of diapedesis by human mature adipocytes. Diabetes 2004, 53:1285-1292.

48. Curat CA, Wegner V, Sengenes C, Miranville A, Tonus C, Busse R, Bouloumie A: Macrophages in human visceral adipose tissue: increased accumulation in obesity and a source of resistin and visfatin. Diabetologia 2006, 49:744-747.

49. Shaul ME, Bennett G, Strissel KJ, Greenberg AS, Obin MS: Dynamic, M2-like remodeling phenotypes of $\mathrm{CD} 11 \mathrm{C}+$ adipose tissue macrophages during high-fat diet-induced obesity in mice. Diabetes 2010, 59:1171-1181.

\section{doi:10.1186/1743-7075-9-3}

Cite this article as: Thomas et al:: A high calcium diet containing nonfat dry milk reduces weight gain and associated adipose tissue inflammation in diet-induced obese mice when compared to high calcium alone. Nutrition \& Metabolism 2012 9:3.

\section{Submit your next manuscript to BioMed Central and take full advantage of:}

- Convenient online submission

- Thorough peer review

- No space constraints or color figure charges

- Immediate publication on acceptance

- Inclusion in PubMed, CAS, Scopus and Google Scholar

- Research which is freely available for redistribution

Submit your manuscript at www.biomedcentral.com/submit
Biomed Central 